\title{
Das cinzas à purpurina: bichas que cintilam em leitura e escrita biografemática
}

\author{
From ashes to glitter: \\ queers that sparkle in biographematical reading and writing
}

Tales Santos Pereira

Universidade Estadual de Santa Cruz

André Luis Mitidieri

Universidade Estadual de Santa Cruz

DOI: https://doi.org/10.5902/2176148537310

RESUMO: Pela perspectiva biografemática, conforme proposição de Roland Barthes, propomos uma leitura homoerótica da narrativa jornalística de cunho biográfico "Manuel nunca dijo adiós", de Tomás Eloy Martínez, e do roteiro cinematográfico La tajada, de Manuel Puig, a fim de flagrar vestígios e pormenores de identidades e subjetividades homoeroticamente inclinadas. Dessa forma, os biografemas revelados, em cenas de flertes, paqueras, flashes da infância e memórias de grandes ícones, constituem-se enquanto operacionalizações para discussão das representações da dissidência sexual e da multiplicidade de agenciamentos, modos de ler, ser, viver e interpretar o mundo.

PALAVRAS-CHAVE: Espaço biográfico. Homoerotismo. Manuel Puig.

ABSTRACT: From a biographematical perspective, as Roland Barthes' proposition (1990), this paper proposes a homoerotic reading of the biographical journalistic narrative "Manuel nunca dijo adiós" ("Manuel never said goodbye"), written by Tomás Eloy Martínez, and of the script La tajada (The slice), written by Manuel Puig, seeking to detect vestiges and small details of homoerotically inclined identities and subjectivities. Thus, in scenes of flirting, childhood flashes and memories of great icons, the revealed biographemes constitute a space for discussing representations of sexual dissidence and the plurality of agency, ways of reading, being, living and understanding the world.

KEYWORDS: Biographical Space. Homoerotism. Manuel Puig. 


\section{PORMENORES E PURPURINAS}

Bicha não morre, vira purpurina.

Vera Verão

Tales Santos

Pereira

André Luis

Mitidieri

258

Valendo-nos do mote protagonizado por Vera Verão, personagem imortalizada pelo ator Jorge Lafond, um dos ícones gueis da televisão brasileira, procuramos delinear um espaço de discussão que insira registros (auto)biográficos das subjetividades homoeróticas e sinalize à revisão da "heteronormatividade" que, segundo Michael Warner (1993), privilegia a cultura heterossexual como a única maneira de interpretar, ler e viver as relações em sociedade. Assim, o modelo "heteronormativo" instala-se como parte de uma ideologia totalizante inerente às relações de gênero e estrutura posições de poder, modos de pensamento e padrões comportamentais; subscreve a heterossexualidade homogeneamente nos corpos, como predisposição natural e correta de organizar a sexualidade.

Aqui entendemos como basilar o conceito de "biografema", do teórico francês Roland Barthes (1990), porque traz novas perspectivas de representação do indivíduo pela e na linguagem, sobretudo frente aos dilemas das subjetividades na contemporaneidade, pois diferentemente do que podem pressupor expectativas mais ingênuas, o ser não pode confiar na ilusão da forma singular, que o componha na sua totalidade. Uma vez que cacos estilhaçados do indivíduo se depositam na escrita, não respondem por uma unidade íntegra, mas se movimentam numa rede potencialmente sígnica, em processo de legítima alteridade, porque a restituição do Outro refrata a nossa própria multiplicidade, levando-nos a questionar estruturas de poder que a negam a e a interditam.

Entre a configuração do ser e os dilemas das narrativas biográficas, funda-se terreno flutuante - o "espaço biográfico" - caracterizado pela "recorrência antes da singularidade; a heterogeneidade e a hibridização em vez da 'pureza' genérica; o desdobramento e a migrância em vez das fronteiras estritas; em última instância a consideração de um espaço biográfico como horizonte de inteligibilidade" (ARFUCH, 2010, p. 16). Amparados sob essa perspectiva teórica, compreendemos a escrita biográfica articulada com os modos como as vidas são (re)lidas na conformação da biografia, pois se antes os seus paradigmas "clássico" - estendido da Antiguidade ao Século das Luzes - e "romântico-positivista" - instaurado ao final desses anos - em geral, tiveram como traços 
comuns o foco nos "grandes homens", o primado das narrativas lineares e certo respeito à cronologia (MADELÉNAT, 1983), tais concepções não oferecem suporte aos dilemas de sujeitos fragmentados, distantes de um núcleo essencialista do "eu".

Com frequência, nos modelos canônicos das biografias, uma linha ascendente de glória e prestígio erigia-se em torno à figura do herói dotado duma vida singular e, por si mesma, merecedora de ser biografada. Sobretudo em formatações anteriores à biografia "moderna" (MADÉLENAT, 1983), privilegiava-se uma categoria prevista de personalidades: valorosos heróis, imperadores, reis, soldados, generais etc. Notáveis acontecimentos por eles conduzidos normalmente não ultrapassavam o entorno dos centros de poder, de modo que o gênero se tornou hábil em negligenciar acontecimentos às margens.

Das cinzas à purpurina

Ao acompanhar discussões desse porte, François Dosse (2007) evidencia uma transformação das perspectivas identitárias contempladas pelas narrativas biográficas:

O regime da historicidade moderna destrói as figuras tutelares adequadas para a identificação. Esta desconstrução reabre o campo de possibilidades das figuras plurais. o biógrafo pode, então, aproveitar-se dos índices mais suscetíveis para compor agenciamentos biográficos segundo linhas de intensidade múltiplas. A linearidade postulada pela biografia clássica deixa de ser considerada intocável. o fato de considerar o homem como fundamentalmente plural, atravessado por seus diversos pertencimentos, modifica a maneira de abordar o gênero biográfico (p. 297, tradução nossa).

Quando se reconhece o indivíduo na pluralidade que o constitui, a possibilidade de leitura de outras vidas potencializa a percepção sobre as diferenças, pois encaminha ao questionamento da identidade enquanto constructo essencialista e autenticador. Partimos então do conceito de "biografema", estabelecido por Barthes (1990) ao analisar as vidas dos autores destacados no título de Sade, Fourier, Loyola. O semiólogo homossexual parece realizar o desejo antes explicitado em Roland Barthes por Roland Barthes (2003) quando se narra através de pequenos detalhes e prioriza uma (re)leitura da própria vida, "como dito por uma personagem de romance" (p. 11). 
A partir desse texto autobiográfico, mas que desafia recorrências do gênero, porque além de assumir possibilidades de ficcionalização, se vale da terceira pessoa, própria das biografias, Costa (2010) compreende o biografema

Tales Santos

Pereira

André Luis

Mitidieri

260
[...] como aquilo que se consegue escrever ao $<$ do $>$ autor o qual se lê e se ama, que leva o biógrafo a reencontrar uma tenuidade da lembrança. Uma lembrança que não convoca a memória pregressa, mas que a atualiza nestes encontros entre aquele que escreve e aquele sobre o qual - apaixonadamente - se deixa escrever. Escrileitura. Testemunho daquilo que faz corpo entre o escritor-leitor e seu autor amado. Uma atualização que sempre traz consigo a névoa de possibilidades virtuais, uma refrescante umidade ao ressecamento dos cérebros históricos (p. 108).

Se discussão empreendida por Barthes figura em um contexto onde o pós-estruturalismo acabava de assinalar a morte do autor, o procedimento biografemático convoca amigavelmente o seu retorno, não em termos de unicidade absoluta, mas a fim de compor um corpo escritural por via metonímica: ao envolver o indivíduo pelo potencial dissociador, deposita na textualidade fragmentos refratados num caleidoscópio pulverizador, do plano da criação ao da leitura. A dinâmica biografemática explicita determinada impossibilidade de acessar a essência de um sujeito disperso, esmaecendo o seu núcleo de identificação. Ao viabilizar fantasmas e imagens tênues, agregados a uma cartografia pessoal, por meio de perspectivas sempre provisórias, não é o polígono que desvela, antes, um de seus lados ou, como Barthes (1990) adverte:

O autor que volta não é por certo aquele que foi identificado por nossas instituições (história e ensino de literatura, da filosofia, discurso da Igreja); nem sequer é o herói de uma biografia. 0 autor que sai de seu texto e entra na nossa vida não tem unidade; é um plural de encantos; o lugar de alguns pormenores sutis e, todavia, fonte de clarões romanescos, um canto contínuo de amabilidades, em que, não obstante, se lê mais seguramente a morte que a epopeia de um destino; não é uma pessoa (civil, moral) é um corpo (p. 14). 
Os biografemas assumem caráter migratório, transitam da corporalidade narrada às recomposições operadas pelo leitor. Como uma das maneiras de transformar o texto em objeto de desejo e exercício de convencimento erótico, a leitura biografemática acontece:

Quando o texto 'literário' (o livro) transmigra para dentro da vida, quando outra escritura (a escritura do outro) chega a escrever fragmentos da nossa própria cotidianidade, enfim, quando se produz uma co-existência. 0 indício do prazer do Texto é então poder-se viver com Fourier, com Sade (BARTHES, 1990, p. 11).

Das cinzas à purpurina

O prazer da leitura biografemática volta-se à fruição mesclada ao labor criativo, possibilidade de capturar ressonâncias do corpo reverberado na própria linguagem, enquanto, ao apontar a existência de corpúsculos frente aos "grandes vultos", a escrita biografemática abala versões da história oficial. Por intermédio dos pormenores que engendram, tais procedimentos constroem mosaicos transbordantes nas relações de significados:

o biografema mina os símbolos hierarquizados na medida em que estabelece uma nova ordem para aquilo que a cultura oferece acerca do autor. O biografema coloca-se como entrave à teleologia de certas biografias [...], na medida em que não busca converter o leitor <talvez apenas convencer>. Neste aspecto, o biografema aproxima-se da sensualidade do texto cartesiano <não do seu conteúdo, mas de sua estratégia sensual de convencimento>. O convencimento <diferente do ato de converter> envolve um charme, um gesto errático que sempre denuncia o prazer daquele que se põe a convencer [...] o convencimento não captura, ele insinua. O convencimento não finaliza, ele suspende (COSTA, 2010, p. 108).

A partir dessa reflexão, o biografema permite-nos discutir narrativas afiguradas como forças de dissidência aos discursos hegemônicos e às heteronormatividades, tendo em mente que, durante muito tempo, as representações homoeróticas estiveram nas mãos de homens, brancos, heterossexuais, pertencentes às classes sociais abastadas e às insti- 
tuições vinculadas ao poder, o que levou à imposição de imagens sociais constituídas como desvios dos padrões culturalmente naturalizados e, assim, como ameaças nocivas à sociedade. Vozes solapadas durante os processos de constituição da Verdade histórica, contudo, emergem para questioná-la:

Tales Santos

Pereira

André Luis

Mitidieri

262
[...] há, frequentemente e com justiça, a justificativa de que a história de grupos oprimidos resgata uma memória fundamental para se entender o preço da história dos vencedores, mas para além do ressentimento ou mitificação de uma história de resistências, a construção de memórias alternativas se constitui em um referencial político central para a formação de uma sociedade multicultural (LOPES, 2002, p. 33).

Trajetórias de pessoas homoeroticamente inclinadas, pontuadas por correções, lapsos de memória, silenciamentos e obstruções de discursos, contraditam a história patriarcal e cis-heterocentrada que, por longo tempo, busca domesticar a forma "estranha" (GARCIA, 2000), dando-lhe qualitativos depreciantes. Uma história universal da "bestialidade", composta de todo insumo abjeto, se robustece nas excludências operacionalizadas pelo cânone literário que, de modo geral, confirma imaginários e narrativas infames em torno das sexualidades desviantes.

Entretanto, bases ideológicas sobre as quais a instituição literária escamoteia a violência simbólica que exerce a fim de manter seu afã universalista - como a lgbtfobia, o etnocentrismo, logocentrismo, falocentrismo - veem-se afrontadas por novos agenciamentos. No campo literário, trata-se da disputa por espaços antes negados a autores, temas, perspectivas, personagens, LGBTQI+ e de outras minorias sociais, que reivindicam o direito de (se) representar, contrariando posturas calcadas em centramentos de vária ordem.

É pensando na destituição dos lugares fixos de poder e da homogeneização das subjetividades, que unimos o biografema barthesiano aos estudos sobre homoerotismo, buscando discutir experiências, visões e vivências que, como as de Puig sob a mirada e a pena de Tomás Eloy Martínez, incidam na dissolução de estereótipos e preconceitos fixados pela heteronormatividade. Assim sendo, nem ativo ou passivo, masculino ou efeminado, "fechativa" ou "discreto", nem "pão com ovo" ou "bicha gourmet". Cada "viado" apresenta leituras de mundo, modos 
de construir identidades, estratégias para performar o gênero. Todas elas transbordam dicotomias, pois acompanham a pluralidade constitutiva dos seres, espalhando-se tais como glitters, sinais de teimosa (re) existência.

\section{MANUEL VIROU GLITTER: flashes, flertes, glamour}

No horizonte das subjetividades homoeroticamente inclinadas, verificamos primeiramente a operacionalização de "biografemas" referentes ao escritor e roteirista argentino Juan Manuel Puig Delledonne (1932-1990) na leitura biografemática processada pela narrativa do seu conterrâneo Tomás Eloy Martínez (1934-2010): Manuel nunca dijo adiós (2009, p. 199-218). o marco inicial dessa narrativa reside nas cinzas de Puig, guardadas pela mãe num cálice de metal polido, às quais poderíamos tratar como signos biografemáticos, conforme Barthes (1990) confidencia: "Porque se é necessário que, por uma dialética arrevesada, haja no texto, um sujeito para amar, tal sujeito é disperso, um pouco como as cinzas que se atiram ao vento após a morte" (p. 12).

Em Manuel nunca dijo adiós, a morte não é suficiente para apagar uma existência, tampouco os resíduos incinerados duma existência se fazem necessários para perpetuá-la. Se temos um corpo atravessado pela linguagem, digamos escritural, evocamos nele o "plural de encantos" barthesiano, isto é, configura-se um estatuto para o indivíduo que volta metonimicamente no texto. Martínez (2009) assevera tamanha constatação ao se deparar com os restos mortais do amigo: "en verdad, yo no sabía qué hacer ante aquellas cenizas. Puig no estaba en ellas y tampoco quedaba nada de él en ese cuarto: nada, ni lo que había deseado o imaginado, y menos aún lo que había sido" (p. 200).

Os vestígios fúnebres, nos quais o escritor não se encontraria, levam-nos a evocar a epígrafe introdutória a este artigo: "bicha não morre, vira purpurina". Corpúsculos biografemáticos da narrativa, ressignificados com a presente leitura, revelam uma subjetividade homoerótica, evidenciada em flertes e flagras amorosos, imagens de atrizes glamorosas, flashes de cenas da infância, como num fuxico de retalhos, onde perseguíssemos a passagem do ser humano pelo tempo, que em breve instante se instaura e em outro se dissipa. Na constituição da corporalidade diáfana, o universo guei transparece como locus onde se abrigam subjetividades transitivas, dotadas de configuração não essencialista, pois nutrida de multiplicidade identitária e dos modos de viver a sexualidade. 
Nesse interstício, o espectro homoerótico de Manuel Puig, embora sob a mirada de um autor heterossexual, permite o escape de elementos homoeróticos que sinaliza tratamento sensível às vivências homossexuais, a exemplo de quando o narrador informa sobre o fato de Puig teatralizar um pudor inicial ante a presença dos amantes, referendando a tipologia da loca [bicha] melodramática, identificada por

Tales Santos

Pereira

André Luis Mitidieri Jorge Luis Peralta (2018) no autor e na sua personagem Molina, do romance El beso de la mujer araña: "Manuel me tomó una mano, como si yo pudiera ampararlo. 'Ahí está él. Ahí con su cuadrilla', señaló con su voz sigilosa. [...] Temblaba como un adolescente [...]".

O prosseguimento da situação narrativa - "A él no le gusta que le molesten pero yo no me aguanto [...]" (p. 204) - leva-nos a identificar o biografema do bofe discreto cujas conquistas se pontuam pela presença do sigilo e do segredo. Pelo status dos homens com os quais Puig se relacionava, a discrição é um atributo que possibilita o envolvimento de varões heterossexuais em cenas homoeróticas. Cria-se uma zona de interação onde homens casados e de família não estariam imunes à sedução das bichas: "conocí a dos o tres de sus pasiones en el Village de Nueva York [...]. Todos eran como él decía con falsa modestia de conquistador, 'casados y varoniles"' (p. 208).

No jogo de envolvimentos íntimos, Manuel atira-se irremediavelmente ao encontro do outro; não há condenação estritamente julgada em virtude da homossexualidade latente, mas pelo próprio jogo do infortúnio amoroso, nas ciladas, armadilhas e entraves por ele encetados:

\footnotetext{
Aunque Manuel era receloso, reservado y algo distante, apenas advirtió que yo no iba a condenar su homosexualidad sino más bien a protegerlo de otras condenas, me confió su desesperado amor por un obrero que colocaba tuberías de gas (MARTÍNEZ, 2009, p. 203).
}

O desejo pelo operário que instalava botijões de gás permite situar o biografema do desejo fardado, que povoa o imaginário guei e pode ser exemplificado pelo romance Querelle de Brest, de Jean Genet (1947) e pelas imagens de Tom of Finlad (1920-1991), pseudônimo do artista homossexual Touko Valio Laaksonen, conhecido por desenhar homens fortes e musculosos (soldados, operários, marinheiros, etc) em cenas provocantes e sexuais. Além disso, o discurso direto de Puig, mediado pelo narrador, parece construir imagem ideal do que seria um perfeito 
enlace afetivo e traz à cena o biografema da bicha melodramática, assim reapropriado da tipologia estabelecida por Peralta (2018), e a relembrar o biografema da heroína melodramática, identificado nas personagens baseadas em Eva Perón, construídas pelos escritores gueis argentinos Copi e Néstor Perlongher, nas quais sobressaem "a dimensão simbólica, a emocionalidade e o gestual” (MITIDIERI, 2015, p. 62) típicos do melodrama como gênero relacionado à modernidade:

'Soy una mujer que sufre mucho', me dijo. 'Si pudiera, cambiaria todo lo que voy a escribir en la vida por la felicidad de esperar a mi hombre en el zaguán de la casa, con los rulos hechos, bien maquillada y con la comida lista. Mi sueño es un amor puro, pero ya ves, estoy condenada a los amores impuros' (MARTÍNEZ, 2009, p. 203).

\section{Das cinzas à purpurina}

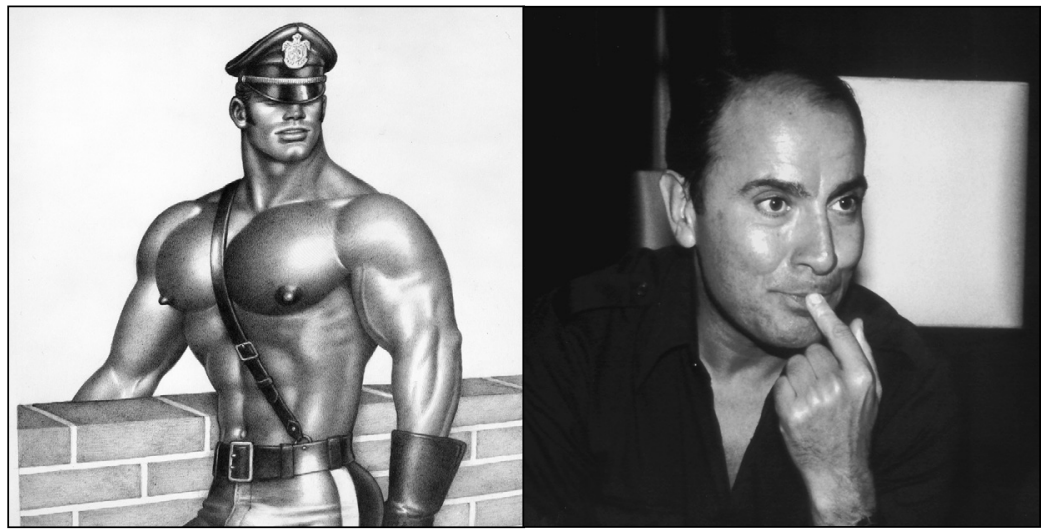

Figura 1 - Gravura de Tom of Finland. Fonte: Tom of Filand Foundation. Disponível em: https://www.tomoffinlandfoundation. org/foundation/NHome.html.
Figura 2 - Manuel Puig.

Fonte: Archivos El Confidencial. Disponível em: https://www.elconfidencial.com/cultura/2018-11-14/manuel-puig-manuel-guedan-

-literatura-max-factor_1643723/.

Em uma leitura superficial, aceitaríamos sem suspeitar a ideia do amor puro, identificado com o modelo da heteronormatividade, da zelosa dama que espera o marido em casa. Contudo, a encenação de um travestimento idealizado, caricatura da projeção do amor ideal, na verdade, debocha dessa instância do status quo heteropatriarcal. $\mathrm{Na}$ identificação social de um guei homem com performatividade feminina, engendrada na dominação masculina, instaura-se a rasura aos papeis sociais masculinos orientados pela matriz heteronormativa. As- 
Tales Santos

Pereira

André Luis Mitidieri

sim, como sua personagem Molina, de El beso, o Puig narrado por Tomás Eloy Martínez, ao se valer da performance de "referir-se a si mesmo no feminino e apaixonar-se reiteradamente por homens heterossexuais" (ALÓS, 2013, p. 121) não se vê convertido "materialmente em uma mulher heterossexual [...] ao invés de subscrever o caráter binário dos códigos de sexo e de gênero, questiona a própria possibilidade de uma matriz dicotômica produzir identidades de gênero e de sexualidade, ao mostrar o quanto são frágeis os seus limites classificatórios" (ALÓs, 2013, p. 121-122).

Dessa forma, Puig traça uma estratégia alternativa à dominação simbólica acentuadamente masculina, que assinala as culturas hispânicas e, assim, a cultura argentina. Importa lembrar que, roteirista cinéfilo, o escritor não passou imune pelas celebridades femininas da grande tela, em especial, no que diz respeito aos modos de subjetivação por elas estruturados, como paralelo confrontador aos padrões heteronormativos, pois "toda uma ampla galeria de personagens femininos, históricos ou ficcionais, é alcançada à condição de ícone cultural e, desse modo, serve à articulação discursiva das experiências de vida de homens gays" (BARCELLOS, 2006, p. 421).

No caso de Puig, nomes como Rita Hayworth, Greta Garbo, Linda Darnell, Beth Davis, Greer Garson, entre outras, representam nos gestos que encenam - quer na vida pública, quer seja sob o brilho dos palcosatos políticos adornados por uma estética particular. Nesse sentido, as bichas transformam o corpo em palco por intermédio da (re)invenção de identidades, ao se utilizarem de ícones femininos, os quais:

\footnotetext{
[...] compõem uma verdadeira mitologia contemporânea, que acaba por cumprir um papel análogo ao da mitologia clássica em boa parte da literatura canônica, a saber, prover um chão de sentido sobre o qual construir a própria subjetividade e a partir do qual propor uma leitura de mundo (BARCELLOS, 2006, p. 423).
}

Divas da filmografia norte-americana habitaram o imaginário de Puig, causando-lhe fascínio e deslumbramento. Imagens de mulheres poderosas constituíram o interstício onde depositaria uma parcela do tórrido arrebatamento que nutre pelo cinema, levando-o ao travestimento dos nomes dos amigos e do próprio nome, estendendo essas referências aos próprios casos amorosos: 
Aunque yo siempre lo llame Manuel, él se llamaba a sí mismo Rita o Julie, por Julie, Christine, y hablaba de los demás en femenino, dándoles nombres de actrices: Carlos Fuentes era Elizabeth Taylor, Mario Vargas Llosa era Esther Williams, Júlio Cortázar era Heddy; a mí me tocaba ser Faye Dunaway o Jane Russell, actrices que no le gustaban.

A sus amores ocasionales los llamaba sin embargo como a los maridos de Rita Hayworth: Orson (por Welles), Alí (por Alí Khan), Dick (por el cantante Dick Haymes) o Jim (por el productor James Hill, que fue el último) (MARTÍNEZ, 2009, p. 208).

Ainda ao discutir a identificação dos ícones femininos por autores gueis, Barcelos (2006) assinala:

Das cinzas à purpurina

[...] por um lado, temos a identificação do homem gay com uma figura feminina, emblemática enquanto objeto de desejo [...]; por outro, temos [...] a constatação, formulada de uma maneira quase infantil, da vulnerabilidade social que afeta de modo particular os gays. Há, pois um movimento simultâneo de identificação imaginária com uma posição de poder, no campo do erotismo, da sedução e do glamour, e da constatação de uma realidade insofismável, qual seja a posição de fragilidade e vulnerabilidade do homem gay, no campo das relações sociais e políticas efetivas (p. 425).

Podemos observar o que elucida Barcellos quando Puig é inquirido pelo narrador a respeito de relações sexuais com o sexo oposto:

\footnotetext{
Una noche de diciembre, en el vestíbulo del Caracas Hilton, vimos a una mujer muy hermosa que pocos años antes había sido Miss Universo. La belleza trabajada y un tanto boba de la mujer me dejaba frío, pero Manuel quedó seducido en el acto. ‘¡No sabés cuánto daría por ser ella!', me dijo. Sentí una invencible curiosidad y me atreví a preguntarle: ‘¿Alguna vez hiciste el amor con una mujer, Manuel? ¿Alguna vez lo harías? Me miró y, con toda seriedad, me dijo: 'Cuando era chico soñaba con eso. Ahora pienso que, si lo hiciera, sería sólo una vez, por curiosidad, para saber cómo es. Dos veces sería una perversión' (MARTÍNEZ, 2006, p. 209).
} 
Tales Santos

Pereira

André Luis

Mitidieri

268
Em um primeiro momento, Puig toma a modelo como um objeto de desejo, tanto que exprime a vontade de ser como ela, atentemo-nos também ao fato de que a mulher fora Miss Universo, envolvendo-a em uma aura de poder e glamour. Manuel expressa devoção àquela figura, elevando seu desejo ao patamar da curiosidade. Passado tal nível, a persistência do desejo sexual recai no campo da profanação, haja vista que a Miss já fora entronizada no rol de suas deidades.

Por fim, através de lampejos da infância do escritor, descobrimos as motivações da sua paixão pelo cinema, como também as situações de violência simbólica vivenciadas na escola e na família:

Fue en esas vísperas del fin de su novela [...] cuando me presentó Male, su madre, y empezó a contarme algunas historias de su infancia. Sentirse incomprendido era el estigma que más le pesaba. Su padre, Baldomero Puig, un fraccionador de vinos que a mediados de la década de los veinte se estableció en General Villegas, no entendía los ensueños del hijo e intentaba cambiarlo a fuerza de castigos. Male era entonces empleada de una farmacia y su pasión era ir los miércoles al cine, a la doble función vermouth donde pasaban las películas románticas de Bette Davis, Norma Shearer, Greer Garson, Ann Sothern e Irene Dunne. Manuel la acompañaba siempre, pero cada vez que los compañeros lo golpeaban en la escuela o se burlaban de él, el padre para endurecerlo le prohibía esos placeres por una semana o dos (MARTÍNEZ, 2009, p. 205).

O pai de Manuel assumia a função de regulamentar e vigilar a educação heterocêntrica, sublimando o que possivelmente fosse um comportamento nocivo à conduta masculina concebida pela cultura patriarcal. As sanções sofridas pelos indivíduos que não se ajustam à heteronorma se distendem também pelo meio social, a cobrar desses sujeitos "desajustados" a mesma vigilância e controle exercidos pela família. Daí a relevância de se pensar nas estratégias de resistência utilizadas pelos sujeitos homossexuais que, diante do apagamento dos seus modos de subjetivação, se veem desafiados a mobilizar o corpo enquanto palco de atuação política.

Além do mais, a potencialidade performativa das bichas possibilita uma série de (des)articulações orientadas para a produção de novas subjetividades, contraproducentes no sentido da cis-heterenorma. Com 
efeito, a análise de Anselmo Alós (2012) sobre a personagem Molina, protagonista da obra El beso de la mujer araña, de Manuel Puig, evidencia o potencial dessa subversão:

Se os papéis de 'homem forte' e 'mulher frágil' são imitações repetidas por homossexuais - sejam homens ou mulheres -, isso requer pensar que esses modelos são imitações condicionadas dentro de um regime heteronormativo, imitações de uma masculinidade e de uma feminilidade idealizadas, desligadas do mundo material, mesmo quando performativizadas por homens Das cinzas à e mulheres heterossexuais. A imitação do feminino realizada por Molina pode ser considerada reacionária em certos aspectos, afinal, ela está baseada nas representações hollywoodianas da feminilidapurpurina de. Mas ela possui um aspecto que extrapola o estereótipo das divas do cinema: uma vez que a femme fatale é reinventada por Molina de modo a colaborar na resistência a um regime totalitário [...] Considerando que a escolha por uma performance de gênero feminino é uma maneira de se opor ao signo da opressão patriarcal [...] Molina não se sacrificou apenas por uma, mas por duas lutas revolucionárias: a subversão das políticas ditatoriais argentinas e a subversão das políticas heteronormativas de sexo-gênero (p. 172-173).

Dentre possíveis respostas às imposições da heteronormatividade, as imagens das divas servem para agregar estratégias de subversão a essa lógica, tornando-se espaço de performatização para sexualidades desviantes. Tamanho travestimento investe-se de uma parodização constante, de um humor que se permite zombar das estruturas de dominação, de posturas e atos que distorcem papéis sociais engessados, pelo entendimento de que os gestos corporais podem figurar como campo de performance política:

Entre junio y julio, Puig y el director de teatro Miguel Sabido se encerraron a trabajar en una nueva comedia, El misterio de un ramo de rosas, pero cuando tardaban más de dos horas en el estudio, los otros amigos se impacientaban y los arrastraban a bañarse en la pileta, imitando las coreografías de Busby Berkeley en Ziegfeld Girl o repitiendo una y otra vez, hasta la extenuación, el número de Rita Hayworth con el guante en Gilda 
mientras los parlantes repetían, a todo volumen, la desesperada invitación sexual de Rita, Put the Blame on Mame (MARTÍNEZ, 2009. p. 203).

Puig confunde-se com as celebridades que admira, a exemplo de quando assume o papel de Rita Hayworth na icônica cena de Gilda, e se

Tales Santos

Pereira

André Luis Mitidieri despe de luvas imaginárias, marcando a encenação de um corpo não enclausurado por identidades fixas. Gilda é Manuel e ambos coreografam identidades configuradas fora do regimento sistêmico das sexualidades, em atos que se revestem do brilho e da beleza de ser quem se deseja ser ainda que, por vezes, essa ocorrência aconteça apenas no âmbito privado.

Num processo de transfiguração, as cinzas do escritor convertem-se em glitter e em gloss, biografemas desprendidos ao longo da narrativa martineziana, pontos luminosos que permitem capturar elementos talvez invisibilizados em narração de caráter mais totalizante. A purpurina ressignifica o ato de decompor-se, não é resto fúnebre de um corpo orgânico, mas a celebração da diversidade de relações e interações que a norma não prescreve nem gerencia. Cintilantes de brilhos e bulhas, de plumas e penas, as bichas encenam - nos corpos cingidos de resistência - a pluralidade de vozes, identidades, sexualidades, modos de relações. Por isso mesmo, não morrem, pois tantas e múltiplas, deixam espectros radiantes sob tempos cinzentos de ódio e intolerância.

\section{BENDITAS SOIS BICHAS ENTRE AS DIVAS!}

Verificamos, no procedimento de escrita biografemática de Manuel Puig (1966), em seu roteiro cinematográfico La tajada, a operacionalização de biografemas referentes a grandes divas, a exemplo de Eva Perón e Rita Hayworth, por meio dos quais, o autor aloca, nos corpos dessas personalidades, fragmentos de subjetividades homoeróticas a fim de compor ambiente de inspiração da sua protagonista Nélida Cuenca. Elaborado por volta de 1960, o referido texto contém diversos elementos que atestam vinculações entre a produção literária e cinematográfica de Puig (ROMERO; GOLDCHLUK, 1998).

A experiência do cinema, na vida e na obra do escritor argentino, configura um espaço de subjetivação do ser homossexual frente aos elementos simbólicos dispostos na construção identitária. Desde criança, ele nutria a paixão pela sétima arte, tanto que, entre suas 
memórias afetivas, constam idas às matinês em companhia da mãe, quando assistiam aos clássicos em preto-e-branco de Hollywood, com lindas mulheres e suas histórias de amor, ódio, vingança, paixão etc. No conjunto de sua obra, a articulação de estratégias de subjetivação pelo cinema aproxima-nos do conceito de "cinefilia gay", proposto por Alberto Mira (2013):

La identidad homosexual tiene una vertiente psíquica, pero la psique queda acotada, estructurada, por discursos que se sitúan fuera de ella: la identidad como concepto siempre participa de Das cinzas à lo individual y de lo social. Para algunos el cine ha sido alimento de modos de identidad, para otros la experiencia del cine ha tenido que ver más con el deseo. En algunos casos, el cine conspurpurina tituía el deseo o la identidad de manera metafórica, en otros simplemente proporcionaba información sobre el mundo, sobre el lugar que uno ocupaba en el mismo (p. 04).

Anterior ao plano de produção cinematográfica que passou a contemplar sujeitos homoeroticamente inclinados, esses tinham como referências melodramas e musicais estrelados por divas espetaculares. Sendo assim, a estratégia de roubar sentidos para constituir um acervo simbólico daquilo que não lhes fora exatamente direcionado

territorializa la relación con el cine estableciendo cánones, íconos, un repertorio de gestos, géneros, personajes y frases; la cinefilia convierte el acto convencional, incluso cotidiano, de ver cine, en un discurso compartido que apunta a la mitología. Uno de los puntos distintivos de la cinefilia es precisamente el papel extraordinario que se da al cine como herramienta epistemológica, como imago mundi. La cinefilia gay utiliza esta actitud básica de maneras que, como veremos, son recurrentes y precisas (MIRA, 2013, p.04).

Desse modo, La tajada sinaliza para a relação entre o universo homoerótico e o rol de notações culturais escolhidas para compô-lo, possibilitando assinalar os biografemas da divice, da bicha maldita e da bicha produtora, por meio dos quais, cintilam as presenças das estrelas do cinema no imaginário guei e dos "viados" que as endeusam no 
Tales Santos

Pereira

André Luis Mitidieri panteão de suas divindades. Assim, vemos a ascensão da personagem de Puig - a atriz Nélida Cuenca - nos anos de 1944 a 1950, a qual representa ecos de divas que tanto o encantaram e assumem trajetória ascendente: do ambiente de pobreza às glórias dos palcos.

Tanto Eva Perón quanto Rita Hayworth compartilharam o mesmo caminho tortuoso até o sucesso. Diante de tantos papéis secundários, humilhações por diretores e casos furtivos que lhes concederam oportunidades, esses ícones femininos não aparecem do nada. Pela identificação do caminho difícil até a fama, elas marcam presença entre os gueis, que leem a si mesmos naquelas que vencem na vida e performatizam atos de glamour, sedução, erotismo e poder. As divas tornam-se fator de inteligibilidade da própria experiência homossexual, além de criar toda uma mitologia de gestos, cenas, personas engendradas pela formação de códigos homoeróticos para a leitura desses elementos (BARCELLOS, 2006). Em relação aos bastidores desse processo, o biografema da divice revela o aprendizado de códigos, gestos e posturas que permitirão identificá-las como tal, por meio da figura de Nélida.

$\mathrm{Na}$ ação narrativa, essa protagonista transita de garota suburbana a estrela do cine argentino, gestando-se em espaços que representam estágios de formação: teatro experimental, teatro de revista, teatro profissional e o esperado Éden - o Cinema - locais que assumem caráter pedagógico na construção do corpo da futura atriz. Primeiro de tais estágios, o teatro experimental coloca-a frente a um tensionamento entre o papel almejado e a falta de referências para executá-lo. Num ensaio da peça La Comandante Bárbara, na qual representaria a personagem principal, o diretor aponta falhas na tentativa de encenar uma mulher de classe:

Director: [...] Nélida, me estás volviendo a hacer pavadas con las manos. Bárbara es una chica bien, pero los meñiques no tienen nada que ver con eso.

Nélida: No me diga que cuando Bárbara señala el cielo y yo hago el ademán para arriba así, (hace ademán, meñiques arqueados) no queda más fino, más delicado..

Director: No, eso no es fino, es cursi. Una mujer de cuna es más natural, no está consciente de sus movimientos (PUIG, 1996, p. 127-128). 
Ao voltar para casa, a jovem atriz dá-se conta de que precisa de outro ambiente para assimilar as referências através das quais irá compor a performance que lhe corresponde no palco, pois em casa, não possui um referencial feminino para tanto:

Madre: Nena, a qué hora termina el Maipo?

Nélida: A la una creo, como todos. Por qué? (mira los torpes modales de su madre al comer) (se siente profundamente deprimida) (PUIG, 1996, p.134).

Das cinzas à

Nélida: Ay Yaya, tengo tantos problemas todo me va mal....

Yaya: Qué pasa?

Nélida: El viejo está infernal. Y mamá no viste mamá?... Pobre, purpurina me da lástima, pero me pone los nervios de punta. [...] Nélida: No, es la mentalidad de ella. Cuando durante toda la vida te tenés que medir hasta el último centavo, qué querés...[...] Y qué ganó con tanto trabajar... qué la hija la mire con asco porque no sabe comer (PUIG, 1996, p. 136-137).

Assim como Eva Perón e Rita Hayworth tiveram casos amorosos que pareceram abrir-lhes portas ao sucesso, Nélida encontra Barrios, responsável pela produção de um espetáculo num teatro de revista. Entre o dilema de ser corista e a reprovação dos pais em vê-la nessa ocupação, a atriz decide morar na casa de sua amiga Yaya. A simples mudança de ambiente desperta-lhe a possibilidade de atingir seus objetivos; consciente disso, a amiga prevê um cenário favorável:

Yaya: Mira, todo esto puede estar a tus pies si te rompés un poco. (Nélida mira los letreros de cines y teatros) En los cines vas a ver tu nombre, en los teatros tu nombre, llegás a un restaurante y te dan la mejor mesa, vas a una boite y todos los tipos quieren estar con vos para darse corte... Yo me quedé por la mitad porque soy media fulera, pero vos... Nélida: Yo más que nada quiero ver mi nombre al tope de un cartel.

Yaya: Y bueno, para qué tenés a Barrios? Dónde vas a encontrar otro que pague como él. Antes de probar la mercadería.... (PUIG, 1996, p. 147). 
A estreia como corista é pontuada por um clima de insegurança, mas o instinto de diva a projeta para o êxito, como se o palco fosse ambiente naturalizado de sua ação no mundo:

Tales Santos

Pereira

André Luis

Mitidieri

274

Nélida en shorts espera las indicaciones de Barrios, sentado en la platea. Ambos miran al pianista, que está buscando partituras. Nélida está aterrorizada, pero tiene su empeño puesto en salir del paso. Su figura luce muy bien en escena.

Barrios: (al pianista) No busque más, cualquier música de pasarela sirve. (el pianista empieza a tocar sin partitura) Nélida, adelante, el paso que te enseñó Yaya... (Nélida avanza insegura) Alta la cabeza... media vuelta.., paso más corto... ahora más largo y pausado... (Nélida se va afianzando) Otra vez paso corto... Mejor... Ahora largo y pausado, no, saltando un compás... eso... (Nélida pone en juego toda su intuición; pese a su falta de experiencia deja entrever una cualidad escénica atractiva) (PUIG, 1996, p. 156).

A necessidade de performatizar a diva dá-se inclusive fora dos palcos ou, dito de outra forma, em outros cenários. Quando conhece Julio, membro da alta sociedade, Nélida percebe o quanto ainda se porta como suburbana, pois ele tem vergonha de lhe apresentar à família:

Nélida: (saca el disco) Como yo, querés decir: que quiero ser fina y no sé qué... y no soy nada. Si, algo soy:.... Soy cursi! (se da vuelta para ocultar los ojos llenos de lágrimas)

Julio: Si seguís así me voy! (Nélida empieza a llorar, él la abraza) Pero qué te pasa? Vas a llorar por semejante pavada... una discusión tan tonta...

Nélida: (siempre abrazados) No es la discusión, soy yo que me siento tonta... Ay, Julio, ayúdame! (se ciñe a él) No quiero ser cursi, ni todo lo que decís vos, enséñame a ser como te gusta a vos...! Yo no tengo nadie de quien aprender (PUIG, 1996, p. 172).

Ao mudar-se para o apartamento de Julio em um bairro nobre, a protagonista começa sua aprendizagem de novos costumes. Há todo um acervo pormenorizado de referências que a jovem atriz observa nesse ambiente: passear pela vizinhança, frequentar as finas confeitarias, observar o comportamento das mulheres vizinhas, tudo serve como maté- 
ria para apreender o código daquele novo e requintado ambiente. Nesse ponto do texto, ela segue um caminho que vai desde o cursi - brega, cafona - até a postura de elegância e fineza:

Julio sale. Nélida se pone un deshabitué ligero, de color claro. Se retoca el peinado. El comportamiento de Nélida es ahora aplomado, sus movimientos son medidos y elegantes. Su arreglo es propio de una dama de gran clase. La transformación iniciada en escenas precedentes se ha completado (PUIG, 1996, p. 175).

Discutindo a questão desses gestos simbólicos, Barcellos (2006) analisa como autores homossexuais os traduzem na leitura de suas experiências. Para tanto, parte do romance de Alonso Sánchez Baute, Al Das cinzas à purpurina diablo la maldita primavera:

\footnotetext{
Ao identificar-se com a Princesa Grace no percurso ascensional que arranca de uma suposta origem modesta que ambos compartilhariam, o narrador rompe com qualquer possível abordagem essencialista e autenticadora da questão da identidade, deslocando-a para o âmbito da experiência da desigualdade e da luta por um lugar ao sol que esta implica. Ser fina e elegante é, nessa perspectiva, o resultado de uma luta num mundo marcado por conflitos e não, uma essência abstrata e a-histórica dada de antemão (p. 428).
}

Após transitar pelo teatro experimental, pelo teatro de revista, Nélida ganha um papel no teatro profissional. Ao sair paulatinamente do amadorismo e do anonimato, desfaz-se do corpo de suburbana, assumindo pose e glamour. 0 modo como encara esse novo palco acompanha-se das referências absorvidas no processo de autoconstrução:

En planos sucesivos rápidos vemos a Nélida iniciar el ensayo. Correcciones del Director, luego expresión aprobadora del mismo. Director contento, afianzamiento de Nélida en su juego. Entusiamo. Pizarra anuciando segundo ensayo; Director y empresario comentan la capacidad de Nélida; se le entregan nuevas hojas de agregado a su papel. Nélida se siente dueña de una nueva fuerza y empuje (PUIG, 1996, p. 182). 
Gestando-se a cada novo papel desempenhado, a atriz alcança o tão desejado papel no cinema. Agora, encontra-se casada com um deputado do governo peronista e prepara as gravações do seu filme:

Set de filmación. Se está ensayando una escena, el decorado donde se filma representa una sala de una lujosa mansión, con

Tales Santos

Pereira

André Luis

Mitidieri

276

gran terraza. Protagonistas de la escena son Nélida y un galán joven. Todos parecen estar pendientes del iluminador, el cual se está ocupando de colocar las últimas luces (PUIG, 1996, p. 187).

Nesse ponto do texto em estudo, a protagonista confunde-se com a sombra de Eva Perón, pois sua performance igualmente transita entre as telas do cinema e os palcos do poder. Tanto Eva quanto Nélida extraem das artes dramáticas as chaves do desempenho político:

Ayudante: [...] Señor, el marido de Nélida acaba de llamar, que viene a buscarla para un acto oficial.

Director: ¿Cuando?

Ayudante: Tiene que estar lista dentro de quince minutos.

Director: ¿Qué??? No!!! Esto es ya demasiado... (arroja con estruendo el libreto y sale) (PUIG, 1996, p. 189-190).

Na transformação final de Nélida Cuenca, notamos um componente biografemático, pois os detalhes mobilizados para a construção da imagem da diva - gestos, poses e movimentos - compõem um códice próprio a sujeitos homoeroticamente inclinados, que consiste na imitação das estrelas admiradas. Dessa forma, depois de passar pelos rituais adequados, a protagonista eleva-se ao status daquelas figuras com as quais se identificava nos cartazes de cinema nos momentos antes da fama:

Al terminar la película se coloca los anteojos ahumados y sale. Se siente mejor que al entrar pero le cuesta dejar la compañía de Claudette Colbert, Jennifer Jones y demás, esos seres perfectos con quienes se siente tan a gusto. En el hall se detiene a mirar los carteles de la misma película que acaba de ver, para prolongar por unos segundos más los placeres de la ficción (PUIG, 1996, p. 160). 
A trajetória de construção das estrelas não prescinde dos contatos com gueis, dos quais recebem dicas ou lições, por vezes, severas alfinetadas, e com quem compartilham experiências de vida. No roteiro em análise, essa figura encontra-se no diretor do teatro experimental onde Nélida começou a carreira, habilitando-nos a estabelecer o biografema da bicha maldita cuja composição pode ser observada pela rubrica do texto: "Director: (personalidad afeminada, cabello largo, aspecto descuidado) (a la dama joven) Nélida, me estás volviendo a hacer pavadas con las manos. Bárbara es una chica bien, pero los meñiques no tienen nada que ver con eso" (PUIG, 1996, p. 127).

O sarcasmo e deboche encarnado constituem um modo de ler as normas impostas pela heteronormatividade. Assim nasce a bicha maldita: com o peso e a graça do verbo ofídico e impiedoso, nada escapa da Das cinzas à purpurina sua língua afiada e ferina. Em La tajada, é o diretor de teatro que zomba da interpretação de Nélida quando interpreta uma dama da sociedade, acusando-a de cafonice ao exagerar em gestos afetados e, além disso, a provoca, alegando falta de referências sólidas de fino comportamento:

\footnotetext{
DIRECTOR: (a Nélida) Ves! Eso es lo que te digo, ese tipo de movimiento! No tenés una amiga bien a quién imitar? Fíjate en los movimientos de ella, no en los de la cocinera. (van hacia el escenario) NÉLIDA: (inmóvil, observando el grupo que se aleja) (herida, para sí) Maricón de porquería (PUIG, 1996, p. 129).
}

Desse modo, “a pergunta 'por que me perseguem' transmuta-se imediatamente em 'por que me odeiam' como se se tratasse de formulações equivalentes e intercambiáveis" (BARCELLOS, 2006, p. 443). Justifica-se, então, a postura defensiva da bicha maldita, pois, considerando que todos a odeiam, desenvolverá "uma atitude defensiva e armada do personagem frente ao mundo e aos outros e [...] novas formas de opressão e exclusão que ele próprio passa a promover" (BARCELLOS, 2006, p. 433).

$\mathrm{Na}$ cena entre o diretor do teatro experimental e Nélida, a bicha maldita reprova a interpretação da jovem porque ela ainda não responde aos códigos de intelecção necessários para sua identificação como uma grande celebridade. Nesse caso, ao debochar da postura em cena da protagonista, o diretor sinaliza que, para a garota suburbana, o caminho de diva ainda está por se construir. 
Analisando o fenômeno da bicha maldita na literatura, Barcellos (2006, p. 433) discorre:

Tales Santos

Pereira

André Luis

Mitidieri

278

[...] o caráter corrosivo ou venenoso de uma vertente do discurso gay é plenamente assumido e legitimado como atitude frente o mundo. Nesse processo, forma estética e postura ética identificam-se de tal maneira, que se tornam indiscerníveis uma da outra. Gesta-se, assim, a imagem da "bicha maldita" (bitch, em inglês; perra, em espanhol) que é uma das figuras mais interessantes da cultura gay.

Assim como Evita deixou-se montar pelo cabeleireiro, que fez do seu penteado uma marca indelével, estrelas aprendem algumas lições, no árduo caminho até a fama e a glória, dos maquiadores, estilistas, figurinistas, responsáveis pelo que denominamos biografema da bicha produtora. No roteiro em análise, esse papel é desempenhado pelo estilista Paco, apresentado por Yayá à aspirante atriz, para ensinar-lhe como desfilar nas passarelas:

\footnotetext{
Yaya: [...] Mira, ahí está Paco.

Nélida: El modisto?

Yaya: Sí, vamos que lo saludo. (Van hacia un hombre de grandes gafas y masculinidad dudosa).

[...]

Paco: Déjame verla... [...]Me gustaría que pasara uno de mis modelos en el diner Golf...

Nélida: Yo chocha.

Yaya: Regio, piba. Yo te enseño a dar los pasos de desfile.

Paco: Qué sabes vos de desfiles, San Lorenzo! (a Nélida) No se preocupe, yo me encargo (PUIG, 1996, p. 151-152).
}

Por certo, as bichas produzem divas em duplo sentido: criam-nas em sedas e maquiagens para adorá-las como objetos de fervorosas devoções. Todo o ritual de criação obedece a um código altamente elaborado: cada celebridade apresenta uma característica marcante, fragmentos biografemáticos que nos remetem aos espectros de uma figura sempre exposta e, portanto, passível de reconstruções narrativas. Nessa "metonímica", lemos Evita pelo coque louro, pelos deslumbrantes vestidos e efusivos discursos; Rita Hayworth, pela beleza mediterrânea, pelos grandes e marcantes olhos, pelas luvas que sensualmente retira das mãos em Gilda. 
Mais do que encantamento, a relação entre divas e "viados" tem outra natureza subjacente, conforme aponta Mira (2014, p. 16):

\begin{abstract}
la voz de la diva resulta mucho más adecuada para expresar sentimientos que tienen difícil acomodo en la retórica del varón heterosexual, cuyo modelo identitario tiene un elemento importante de contención, de no hablar, de no expresar. Personajes como Norma Desmond o Margo Channing hablan mucho y poseen un lenguaje fuerte, que captura la realidad. Ambas tienen un lugar bastante incómodo en el cine: las mujeres del melodrama pagaban su fortaleza, en términos narrativos, con lágrimas; en el cine negro, las mujeres demasiado activas eran castigadas. $Y$ sin embargo, esta idea de lucha contra un sistema que intenta reducirlas al silencio es una característica que las une.
\end{abstract} Das cinzas à purpurina

Nos biografemas anteriormente destacados, notamos subjetividades homoeróticas erigidas na construção de uma diva do cinema. Corpos performatizados do autor e das estrelas comungam de certos ritos: dançam nos mesmos cabarés, flertam em cenários oníricos, choram lágrimas de amargura, sofrem por amores impossíveis, encenando-se como locas melodramáticas. Em Puig, assim nas letras como no cine, as personagens roubam de algumas celebridades eleitas as ações que desempenham na ficção (MIRA, 2014); são elas e os seus fantasmas, vozes, gestuais, corporalidades, textualidades, em constante retradução e remontagem. Em La tajada, a trazer no título palavra traduzida em português como pedaço, fatia, naco, bocado, a escrita biografemática do escritor que repetia exaustivamente a coreografia de Rita Hayworth, performatizando Gilda e o emblemático gesto de se desnudar das luvas, ou que apelidava amigos com nomes de atrizes cinematográficas, podemos ler um corpo divino (de quem está entre as divas).

Nas poses reclamadas e sob luzes da ribalta, Ritas, Greers, Julies, Fayes, Beths, Lindas, Gretas, Normas, Evas, Nélidas, assinalam suas vitórias, não menos sofridas, sobre o mundo fosco, atestando a frescura de ser o que se deseja, como Jorge Lafon transviado em Vera Verão. E há um potencial incomodativo, mas também radiante, na divice das bichas, pois como cantava Lucinha Lins (diva, embora um dia vaiada e hoje, esquecida, como toda celebridade momentânea), "Se você pensa que vai me seduzir/ Se você pensa que vai me arrepiar/Pode ser, mas eu sou feito purpurina/ Se uma luz não ilumina, não há jeito de brilhar". 


\section{REFERÊNCIAS}

ALÓS, Anselmo Peres. A letra, o corpo e o desejo: masculinidades subversivas no romance latino-americano. Florianópolis: Editora Mulheres, 2013.

Tales Santos

Pereira

André Luis Mitidieri

280
ARFUCH, Leonor. O espaço biográfico: dilemas da subjetividade contemporânea. Rio de Janeiro: EDUERJ, 2010.

BARCELLOS, José Carlos. Literatura e homoerotismo em questão. Rio de Janeiro: Dialogarts, 2006.

BARTHES, Roland. Sade, Fourier, Loyola. Traduzido por Mário Laranjeira. São Paulo: Brasiliense, 1990 [1971].

BARTHES, Roland. Roland Barthes por Roland Barthes. Traduzido por Leyla Perrone-Moysés. São Paulo, Estação liberdade, 2003 [1975].

COSTA, Luciano Bedin da. Biografema como estratégia biográfica: escrever uma vida com Deleuze, Barthes e Henry Miller. 2010. 180 f. Tese (Doutorado em Educação) - Universidade Federal do Rio Grande do Sul, Porto Alegre, 2010.

DOSSE, François. La edad hermenéutica (II): la pluralidad de las identidades. In: DOSSE, François. La apuesta biográfica: escribir una vida. Valencia: EdUV, 2007, p. 297-361.

GARCIA, Wilton. A forma estranha: ensaios sobre cultura e homoerotismo. São Paulo: Pulsar, 2000.

JARDIM, Jerônimo. Purpurina. Disponível em: <https://www.vagalume. com.br/lucinha-lins/purpurina.html>. Canção vencedora do Festival MPB Shell 1981, interpretada por Lucinha Lins.

LOPES, Denilson. Bichas e letras: uma estória brasileira. In: SANTOS, Rick; GARCIA, Wilton (Org.). A escrita de Adé: perspectivas teóricas dos estudos gays e lésbic@s no Brasil. São Paulo: Xamã, 2002, p. 15-22. 
MADELÉNAT, Daniel. La biographie. Paris: Press Universitaires de France, 1983.

MARTÍNEZ, Tomás Eloy. Manuel nunca dijo adiós. In: MARTÍNEZ, T.E.. Lugar común la muerte. Buenos Aires: Alfaguara, 2009, p. 199-218.

MIRA, Alberto. Cinefilia gay y el cultivo del yo. Razón y palabra, Monterrey, n.85, dez. 2013- mar, p. 1-24, 2014. Disponível em: <http://www. redalyc.org/articulo.oa?id=199531506002>. Acesso em: 14 de março de 2016.

MITIDIERI, André Luis. Biografemas homoculturais de Eva Perón no romance Santa Evita, de Tomás Eloy Martínez. In: MITIDIERI, André Luis; CAMARGO, Flávio Pereira (Org.). Literatura, homoerotismo Das cinzas à purpurina e expressões homoculturais. Ilhéus (BA): EDITUS, 2015. p. 41-76.

PERALTA, Jorge Luis. Invitados en el paraíso (de las locas). Feminidades masculinas en la literatura y cine argentinos. In: Colóquio Internacional de diversidade sexal e de gênero, Ilhéus, 2018, conferência inaugural.

PUIG, Manuel. La tajada [1960]. In: AMÍcoLA, José (Ed). Materiales iniciales para La traición de Rita Hayworth. La Plata: Centro de Estudios de Teoría y Crítica Literaria, Universidad Nacional de La Plata, 1966.

ROMERO, Julia; GOLDCHLUK, Graciela Goldchluk. Puig secreto, El cuidado de los textos. Hispamérica, Maryland, v. 27, n. 80/81, p. 91-111, 1998. Disponível em: <www.jstor.org/stable/20540070>. Acesso em: 18 fev. 2017.

WARNER, Michael. Introduction. In: WARNER, M.. Fear of a Queer Planet. Queer Politics and Social Theory. Minnesota: University of Minnesota, 1990. p. I-XV. 
